\title{
A Curriculum Model for Developing Teams, Communication Skills, and Introducing the Design Process for Engineering Programs
}

developed by the TIDEE Project Team.

\author{
Kenneth L. Gentili Tacoma Community College \\ Jeffrey F. McCauley Green River Community College
}

Richard W. Crain Jr., Dale Calkins Deceased

Denny C. Davis, Michael S. Trevisan, Forrest Parkay, Larry McKenzie

Washington State University

\begin{abstract}
Faculty struggle to implement outcomes-based engineering education that is needed to satisfy ABET Engineering Criteria 2000 requirements for engineering programs. This paper describes a two-step method for developing teams and communications skills, and immediately exercising those skills in a practical introduction to the team process using a simple PET (polyethylene terephthalate) soda pop bottle developed by the TIDEE (Transferable Integrated Design in Engineering Education) NSF sponsored project. Clearly defined team roles and communication skills are introduced in a manner that allows a group of students to develop the synergy needed for a successful team activity. Then a short design exercise (using a welldefined design process as a guide) is introduced to facilitate a practical application of both the design process and team and communication skills. The TIDEE teaching/learning model links definable steps in the design process to structured team-based learning activities.

\section{Introduction}

A coalition of two \& four year universities and industry collaborated, with NSF funding, to develop meaningful curriculum and assess its' effectiveness. Different schools use the material to fit their individual needs. The curriculum and assessments are easy to use,
\end{abstract}


reliable and are a proven set of materials that provide a structure that develops clearly defined outcomes and assesses how well course objects have been achieved.

TIDEE's (Transferable Integrated Design Engineering Education) curriculum model uses highly structured activities, which can be used for any engineering design class. Students not only learn what the components are within the engineering design process, but they also learn how to effectively employ them using a variety of new techniques. The curriculum effectively develops students' teamwork and communication skills and they learn how to develop and improve their team processes.

The TIDEE model uses a three-step process, which needs to be repeated within an introductory engineering design class. The first two steps create effective teams and engage them in a highly structured short design process. The third step again uses a highly structured design curriculum to more fully develop the student's design capabilities. However, other design problems and processes that have been developed by universities and colleges can also be effectively substituted for the third step.

The first two steps take about five hours of class time and provide students with a rudimentary concept of the design process. They begin to develop fundamental tools on how to apply each component of the engineering design process, improve their communication skills, and develop a more focused and supportive team.

As noted before, this process is repeated later in the quarter by forming a second team to develop their knowledge and skills to a higher level of thinking and interacting. They become much more adept at reflecting on the developmental process as they compare and contrast their team experiences. It improves their ability to develop effective teams in the future.

Assessments clearly indicate that students significantly improve their abilities with each team experience, where the second team experience is where they learn how to apply the process rather than learning what the process is. For example in TIDEE self-assessments, about seventy percent of the students indicate that they have made significant improvement in developing each of the TIDEE competencies during the time when they were with their first team. Surprisingly, the improvement increases to seventy-five percent during the second team experience.

\section{The First Step}

TIDEE has three different first-step curricula. All of these can be used to form any new teams, not just for engineering design, and are interchangeable. It takes about two hours of class to complete this first step. All create and develop four to six member teams. Teams of less than four can effectively solve or work on limited issues, but the size restricts the diversity of input. It is easier to manage team that often doesn't explore enough possibilities. But, the major team functions, like recording the team process and capturing the essence of the team's ideas, are not completed. Their products are usually not as creative as other teams. 
With too many students on a team a situation often develops where not everyone can be as active as they would like to be and they aren't able to express their ideas or contribute as fully. There aren't as many meaningful jobs, which provides a better opportunity for social loafers to "hide" and not engage in the process or have meaningful contributions to the team effort. These large teams generate many good ideas, but have more difficulty making a decision or managing the team.

All three curricula begin the process with an icebreaker activity that creates an atmosphere where students learn the strengths of other team members, barriers are broken down and a more inclusive environment is created. The tone is set giving students permission to use positive and reinforcing language that will more fully support team efforts. All three develop team identity and synergy.

The first curriculum's primary focus is understanding how roles affect teams. Students are introduced to functional roles and eventually each student learns how to manage the team, report team deliberations, record team activities in a team journal, become a checker of product, explorer of new ideas ("the one with crazy and wild ideas"), and to publicly reflect on team process. They are also introduced to the Herrmann Four Quadrant Learning Model. They become aware of other team member's learning styles and the impact that it has on creating more effective designs.

Team members also develop more effective communication skills and learn to be more inclusive. They learn how to give reflector reports, which includes team strengths, team improvements and insights to the process. All of these activities provide the foundation for establishing goals and improving team performance. This results in students listening to each other more effectively, which results in the students setting the bar to a higher level of performance. Teams rise to these expectations and consequently improve their team, communication and process skills.

For the first team, the instructor tries to create teams with diversity of learning styles, has no gender and ethnic person isolated, and examines student schedules to find available times for the team to meet outside class. Over the years we have found that very few introductory students have a B Preference learning style in the Herrmann Model. Because this person will provide organizational skills to the team, it becomes imperative to assign at least one student with this preference to each team.

This demographic information is collected during the first class meeting so that the instructor can arrange the teams prior to the second class. Meeting these criteria provides an atmosphere where every student begins the class at the same place even if "buddies" are taking the class together.

After students have gained experience and confidence, subsequent teams can be selected by the class members or by the instructor. When students select their second team, they should be given the following criteria:

1. Check to see if there is a common meeting time outside class. 
2. Only two members from the previous team may be on the new team so that the new team doesn't bring with it a clique and overpower other new members.

It is interesting to note that when students select their second team, they often ignore or minimize these criteria and establish their primary selection criteria on the personality or strengths of others. Lack of a common meeting time is often ignored, which sometimes produces a conflict that severely affects the team effort until it is resolved. They devise different methods to handle the issue such as keeping excellent notes and passing them from one subgroup meeting to the next, developing a strong leader who coordinates all activities and/or keeping in contact through E-mail. But these methods don't supplant a good face-to-face meeting when all members are present and can instantaneously build on other's ideas. However, even with these limitations, the curriculum supports team development and process improvement and all teams experience the power of a quality team.

The first curriculum has activities that include:

- "Two Truths and a Lie," where the team members must eventually determine two common elements about their team and try to fool the other teams by disguising their lie.

- $\quad$ "Roles for Effective Teams," where students accept a role, discuss previous experience for performing that role, and prioritize the importance of responsibilities within that role.

- $\quad$ "Creating a Team Symbol and Name," which gives the team an identity.

The curriculum develops positive and supportive language used in small group discussion and especially when a team member is communicating in one of the functional roles. Activities include:

- "Killer and Igniter Phrases," where students learn the difference between comments that kill the conversation and process and those that ignite the process.

- "Refining Sounds of Effective Teams," develops igniter phrases for team members to use in each of the team roles.

The third curriculum addresses the issue of how to create more effective teams and how to incorporate and include new members into a team. Activities include:

- $\quad$ "Roles and Responsibilities," where the roles and responsibilities of teams are investigated. Also after roles have been assigned, the teams discuss the anticipated results of not being restricted to a single role and allowing multiple team members to perform different or multiple roles.

- "Strategies for Developing Effective Teams," where teams discuss a variety of issues such as establishing trust and teamwork and helping your team work through strife, gripes and group disagreements. 
- "Integrating New People into the Group" analyzes how well they integrated a new person into their team when members had been snatched from their team and another invited to join while they were engaged in the previous activities.

A sample activity sheet is provided at the end of this paper.

\section{The Second Step}

The second step is a highly structured short design process. Emphasis is on learning what the fundamental components of the design process are and how they can be applied. At the completion of the process there is a group activity that reviews and identifies when specific steps of the design process were undertaken. Even though the students have been through the process, they have difficulty understanding how to identify a particular step, often mislabel a step or combine one.

The TIDEE iterative design process includes the following components:

- Information Gathering - information identified and obtained to support design process and design decisions

- Problem Definition- development of design goals and specific requirements that will ensure a successful design

- Idea Generation-gathering and creating new ideas and concepts for consideration in development of a design

- Evaluation - using appropriate methods and tools to determine how well concepts meet requirements

- Decision Making - making design decisions based on proper consideration of evidence and issues

- Implementation - advancing design decisions toward delivery of design products desired by clients

- Process Development - management of design activities to support effectiveness and improvement

The three short design projects for step two are:

1. Developing a logo for a client.

2. Recycling a PET (polyethylene terephthalate) soda bottle.

3. Developing a problem definition for a team bicycle trip that is to be implemented by a travel agency.

\section{The PET Design}

The PET design process develops all of the components of the engineering design components previously listed. The sequence of the activities is:

1. Identify PET Bottle Characteristics. Requires a minimum of twenty minutes to complete. The instructor might want to use full bottles of soda if he/she wants to 
treat the class. The students gather information about the characteristics of the PET bottle and evaluate which of those characteristics might be useful to consider in a recycling effort. They also need to weigh how a manufacturing process might affect their list of characteristics. Process development occurs when team members learn to effectively listen and build on each other's ideas. Further information is gathered when each team reports (implementation) its findings and a larger, more inclusive list is created.

2. Identify Possible Uses of PET Bottle. Takes about twenty minutes to complete. Each team is to generate at least twenty ideas that identify how a PET bottle could be recycled. Each member is encouraged to contribute to the process. The team reports unique ideas to the class.

3. Identify Criteria for Selecting Best Ideas. Takes about fifteen minutes to complete. Establishing criteria helps to identify the problem definition. Criteria include requirements like safety, appearance, functionality, and manufacturability. The instructor helps the students to understand the difference between a need and a problem definition.

4. Expand List of Ideas. Takes about twenty minutes to complete. The new problem definition creates an iterative effect that allows the students to generate more ideas. They are asked to categorize (evaluation and decision making) their ideas; e.g., toys, containers, etc. They are then asked to seek new ideas within each category and to see if new ideas occur when two categories are bridged.

5. Select the Best Ideas. Takes about fifteen minutes to complete. Each team selects their four best ideas (evaluation and decision making). No reporting done.

6. Evaluation Matrix Decision. Takes about twenty minutes to complete. Each team evaluates its own ideas by using a matrix to select the idea with the greatest merit. The ideas are listed in the columns and each criterion is listed on successive rows. A $(+, 0,-)$ scale is discussed and used to evaluate ideas. No reporting done.

7. Problem Definition. Takes about fifteen minutes to complete. Each team discusses how their product will be manufactured. Each team investigates collection, manufacturing and use issues and writes a problem definition for producing their product. Team writes out their problem definition to be shown on an overhead projector.

8. Implementation Plan. Takes about twenty minutes to complete. Students develop an implementation plan. This activity uses all the steps within the engineering design process. No reporting done.

9. Oral Report on Design. Takes about ten minutes to prepare and about one minute per team to report that describes the project's merits, use and manufacturability. This is an example of implementation.

10. Identify Design Process Steps Used. Takes about fifteen minutes to complete. Each team fills in the following matrix to identify which categories of the engineering design process were completed for each activity of the project.

\section{Identify the design categories for each of the activities of the PET project.}




\begin{tabular}{|c|c|c|c|c|c|c|c|c|c|}
\hline Design Competencies & $\# 1$ & $\# 2$ & $\# 3$ & \#4 & $\# 5$ & \#6 & $\# 7$ & $\# 8$ & $\# 9$ \\
\hline & Charact & Uses & Criteria & Categor & Best & Decide & Prob Def & Implem & Report \\
\hline \multicolumn{10}{|l|}{ Information Gathering } \\
\hline \multicolumn{10}{|l|}{ Problem Definition } \\
\hline \multicolumn{10}{|l|}{ Idea Generation } \\
\hline \multicolumn{10}{|l|}{$\begin{array}{l}\text { Evaluation and Decision } \\
\text { Making }\end{array}$} \\
\hline \multicolumn{10}{|l|}{ Implementation } \\
\hline \multicolumn{10}{|l|}{ Communication } \\
\hline \multicolumn{10}{|l|}{ Teamwork } \\
\hline Process Development & & & & & & & & & \\
\hline
\end{tabular}

\section{Evaluation and Assessment}

Our students come with a mixed set of expectations when they enroll in a team based design course. Often they react from excitement to "Gee whiz, here we go again, another team experience!" A typical team experience is one where the instructor usually assumed that they know how to make the team function and spent little or no time developing team skills. We have assessed entering students and find that they have not developed these skills. And it is not age dependent.

Their previous experience could be described as: "We formed teams, tried to effectively use each of our member's skills, issues emerged that were difficult to resolve, one or more members took up the slack and did most of the work, and somehow we managed to finish the project by the due date and got a reasonable grade."

The class provides "safe situations" so students can take a few risks and try new techniques without feeling that they jeopardize their ability to receive a "good" grade. And they respond with big changes in their lives. They learn how to create highly effective teams where they have experienced what it is like to be part of a high 
performing team. This experience provides them with life-long learning skills that they can use throughout their college and professional carriers.

Beyond understanding the basic components of the design process and developing strategies of how and when to effectively use those components, students developed the teamwork and communication skills that support the design process. For example, they were able to:

- Understand how to use positive, supportive language.

- Create effective roles, a common bond, image and synergy.

- Understand how people with different learning styles contribute to the process.

- Develop intervention techniques when problems arise in communication.

- Develop feedback mechanisms to improve team performance.

- Learn how and when to set goals and to give rewards.

- Break down personnel barriers of being afraid to speak before groups.

- Approach problems in their jobs so that they become more effective team players.

- Train others to form effective teams.

This is confirmed by assessing their skills and knowledge using the TIDEE mid-program and end-of-program assessments, self-assessments, exit interviews, pier reviews of poster presentations and journal evaluations, listening to reflector reports, and using surveys to discover which components of the class are most effective. All evidence indicates that the variety and repetitiveness contributes significantly to the growth in the students' ability to understand the engineering design process, improve communication skills and to know how to form quality teams.

\title{
Activity: Refining Sounds of Effective Teams
}

\author{
Objective: Participants learn to perform their team \\ roles more effectively through use of carefully selected \\ statements
}

\section{Tasks}

Your team's assigned role for this activity is

1. Assign each team member to a role.

2. Review the handout: "Effective Statements for Team Members." 
1. Brainstorm for additional positive statements to be used by persons in your team's assigned role.

2. Brainstorm for negative statements that should not be used in this role.

3. Review your team's recent performance of the assigned role and identify one specific way in which the person in this role can improve team performance through effective use of statements.

\section{Deliverables}

- Team reporter presents on an overhead transparency:

a. Two positive and two negative statements identified for the assigned role.

b. The most effective statement that would support the team's goals.

\section{Criteria for Success}

- Statements are constructive and effective in enhancing team performance.

- Team members have new phrases they could use to make their job more effective.

- Team members have a broader understanding of the job responsibilities within the team.

- Team members have a better understanding of how teaming skills contribute to the success of the project.

\section{Resources}

- Handout that lists effective statements for team members.

- Team member's experience in teamwork.

- Twelve minutes of team discussion time.

\section{Bibliography}

1. ABET. 1998. "Engineering Criteria 2000, Third Edition," Criterion 2. Engineering Accreditation Commission, The Accreditation Board for Engineering and Technology, Baltimore, MD. Worldwide web address: http://www.abet.org/eac/eac2000.htm

2. Woods, Donald R., et al. 1997. "Developing Problem Solving Skills: The McMaster Problem Solving Program." Engineering Education (April): 75-91. 
3. Lamancusa, J.S., J.E. Jorgensen, and J.L. Zayas-Castro. 1997. "The Learning Factory - A New Approach to Integration of Design and Manufacturing into the Engineering Curriculum." Engineering Education (April): 103-112.

4. Davis, D.C., R.W. Crain Jr, M.J. Pitts, E. Rosa, and A. Bayoumi. 1993. Final Project Report for "Engineering in Society: A Broader Professional Curriculum," November, 1993, 71 pp.

5. Davis, D.C., R.W. Crain, D.E. Calkins, K.L. Gentili, and M.S. Trevisan. 1996. "Competency-Based Engineering Design Projects." Paper presented at 1996 Annual Meeting of American Society for Engineering Education, Washington, DC, June 25.

6. Davis, D.C., D.E. Calkins, K.L. Gentili, M.S. Trevisan, J. Hannan, and C.H. Grimes. 1999. "Transferable Integrated Design Engineering Education Project Final Report," Washington State University, Pullman, WA 99164-6120. Web address: www.cea.wsu.edu/TIDEE/

7. Atman, Cynthia J. and Karen M. Bursic. 1998. "Verbal Protocol Analysis as a Method to Document Engineering Student Design Processes." Engineering Education (April): 121-131.

8. Atman, Cynthia J., Justin R. Chimka, Karen M. Bursic, and Heather N. Umphred. (in press). "Comparison of Freshmen and Senior Engineering Design Processes." Design Studies.

9. Smith, Robert P., and Alan Leong. 1998. "An Observational Study of Design Team Process: a Comparison of Student and Professional Engineers," Journal of Mechanical Design, 120(4).

10. Smith, Robert P., and Primanata Tjandra. 1998. "Experimental Observation of Iteration in Engineering Design," Research in Engineering Design, 10 (2): 107117.

11. Davis, D.C., K.L. Gentili, D.E. Calkins, and M.S. Trevisan. 1998. "Mid-Program Assessment of Team-Based Engineering Design: Concepts, Methods, and Materials," Washington State University, Pullman, WA. Web site: www.cea.wsu.edu/TIDEE/

12. Trevisan, M.S., D.I. McLean, D.C. Davis, R.W. Crain, D.E. Calkins, and K.L. Gentili. 1997. "Building a Faculty-Developed Comprehensive Assessment System," presented at Best Assessment Processes in Engineering Education Symposium, Rose-Hulman Institute, Apr.11-12.

13. Trevisan, M.S., D.C. Davis, D.E. Calkins, and K.L. Gentili. 1999. "Designing Sound Scoring Criteria for Assessing Student Performance," Journal of Engineering Education, 88(1):79-85.

14. Trevisan, M.S., D.C. Davis, R.W. Crain, D.E. Calkins, and K.L. Gentili. 1998. "Developing and Assessing Statewide Competencies for Engineering Design," Journal of Engineering Education, 87(2): 185-193.

15. Davis, D.C., R.W. Crain, D.E. Calkins, K.L. Gentili, and M.S. Trevisan. 1996. "Transferable Integrated Design Engineering Education Annual Project Report," Washington State University, Pullman, WA, May.

16. Crain, R.W., D.C. Davis, D.E. Calkins, and K.L. Gentili. 1995. "Establishing Engineering Design Competencies for Freshman/Sophomore Students." 
Proceedings of the Annual Meeting of the American Society for Engineering Education, June 25-28, Anaheim, CA.

17. Davis, D.C., K.L. Gentili, D.E. Calkins, and M.S. Trevisan. 1998. "Mid-Program Assessment of Team-Based Engineering Design: Concepts, Methods, and Materials." Washington State University, Pullman, WA 99164-6120.

18. Gentili, K.L., J.F. McCauley, R.K. Christianson, D.C. Davis, M.S. Trevisan, D.E. Calkins, and M.D. Cook. 1999. "Assessing Students' Design Capabilities in an Introductory Engineering Design Class." Paper number 1356, Proceedings of Frontiers in Education conference, November.

19. Lumsdaine, E., M. Lumsdaine, and J.W. Shelnutt. 1999. Creative Problem Solving and Engineering Design. McGraw-Hill, Inc., College Custom Series, NY.

\section{Biographical Sketches}

Mr. KENNETH L. GENTILI is instructor of engineering and physics at Tacoma Community College. Mr. Gentili has more than thirty years of teaching experience in higher education. During that time he has taught more than twenty-five different courses in engineering, physics and math. He piloted five experimental classes that included a freshman course in Introduction to Engineering Design, Ethical Issues in Engineering, an X-ray Physics class for an occupational program, Application of Numerical Analysis in Physics and Engineering Problems and Environmental Impact and the Law. Mr. Gentili's research is in the field of optics and lasers. He has had international teaching experience in Ethiopia and has developed curricula for elementary school children.

Mr Jeffrey F. McCauley is instructor of engineering and Technology Division chair at Green River Community College. Mr. McCauley has nine years of teaching experience in higher education, and twenty years experience as an engineer in shipbuilding, conversion and repair industry. He has used the TIDEE materials in numerous classes in engineering design and engineering mechanics, and has joined the TIDEE team for the assessment validation and curriculum material development.

DR. RICHARD W. CRAIN, JR. (deceased) was professor of Mechanical and Materials Engineering at Washington State University. He has served as Department Chair of Mechanical Engineering and Dean of the College of Engineering and Architecture at Washington State University. Dr. Crain was a leader in engineering design education, developing courses at freshman and senior levels and integrating writing and social issues into these courses. He has provided significant leadership to curriculum development and assessment in the TIDEE project. He has received local and national recognition for contributions to engineering education.

DR. DALE E. CALKINS (deceased) was Associate Professor of Mechanical Engineering at the University of Washington. He held a joint appointment as Senior Engineer, Applied Physics Laboratory, University of Washington. He had been teaching at the University of Washington since 1979. In 1991, Dr. Calkins received the SAE Ralph R. Teetor Award and in 1993 won the SAE Faculty Advisor Award. More recently he was recognized for outstanding teaching at the University of Washington. 
DR. DENNY C. DAVIS is a professor in the Department of Biological Systems Engineering at Washington State University, where he has served as Department Chair since 1999. He served as Associate Dean, College of Engineering and Architecture, WSU, from 1986-1998. He received a B.S., Agricultural Engineering from Washington State University, and M.S. and Ph.D. degrees in Agricultural Engineering both from Cornell University. Dr. Davis is Project Director for the TIDEE project and has led numerous workshops on assessment of engineering design outcomes.

DR. MICHAEL S. TREVISAN is an associate professor in the Department of Educational Leadership and Counseling Psychology at Washington State University. Since 1997, he has served as the Director, Assessment and Evaluation Center within the department. He received a B.A., Mathematics from San Jose State University in 1983, M.Ed., Educational Psychology in 1988, and the Ph.D. degree in Educational Psychology in 1990, both from the University of Washington. His research interests include educational assessment, applied measurement and statistics, and program evaluation.

Forrest W. Parkay is Professor of Educational Leadership at Washington State University. The recipient of a Ph.D. from the University of Chicago, his research focuses on school restructuring, international education, and curriculum development. He is the author or co-author of several books, including Curriculum Planning: A Contemporary Approach, 7th Edition (Allyn and Bacon, 2000).

MR. LARRY J. MCKENZIE is a second year doctoral student in Educational Psychology at Washington State University. Prior to his graduate studies, he held various leadership and project management positions for 4 years in the U.S. Nuclear Navy, and 18 years with Duke Engineering \& Services of Charlotte, NC. He received a B.A. in Chemistry from West Virginia University. His research interests include assessment in higher education and program evaluation. 